Fixed Point Theory, 22(2021), No. 1, 31-58

DOI: $10.24193 /$ fpt-ro.2021.1.03

http://www.math.ubbcluj.ro/ ${ }_{\text {nodeacj/sfptcj.html }}$

\title{
HÖLDER-TYPE SPACES, SINGULAR OPERATORS, AND FIXED POINT THEOREMS
}

\author{
JÜRGEN APPELL*, ALDONA DUTKIEWICZ**, BELÉN LÓPEZ ${ }^{\dagger}$, \\ SIMON REINWAND ${ }^{\dagger \dagger}$ AND KISHIN SADARANGANI ${ }^{\ddagger}$ \\ *Universität Würzburg, Mathematisches Institut, Campus Hubland Nord, \\ Emil-Fischer-Str. 30, D-97074 Würzburg, Germany \\ E-mail: jurgen@dmuw.de \\ ** Uniwersytet im. Adama Mickiewicza w Poznaniu, Wydział Matematyki i Informatyki, \\ ul. Uniwersytetu Poznanskiego 4, PL-61-614 Poznań, Poland \\ E-mail: szukala@amu.edu.pl \\ †Universidad de Las Palmas de Gran Canaria, Departamento de Matemáticas, \\ Campus de Tafira Baja, E-35017 Las Palmas de G.C., Spain \\ E-mail: blopez@dma.ulpgc.es \\ ${ }^{\dagger \dagger}$ Universität Würzburg, Mathematisches Institut, Campus Hubland Nord, \\ Emil-Fischer-Str. 40, D-97074 Würzburg, Germany \\ E-mail: sreinwand@dmuw.de \\ ‡Universidad de Las Palmas de Gran Canaria, Departamento de Matemáticas, \\ Campus de Tafira Baja, E-35017 Las Palmas de G.C., Spain \\ E-mail: ksadaran@dma.ulpgc.es
}

\begin{abstract}
In this note, we give a sufficient condition for the existence of Hölder-type solutions to a class of fractional initial value problems involving Caputo derivatives. Since imposing (classical or general) global Lipschitz conditions on the nonlinear operators involved leads to degeneracy phenomena, the main emphasis is put on local Lipschitz conditions or fixed point principles of Schauder and Darbo type. To this end, we study continuity and boundedness conditions for linear RiemannLiouville operators and nonlinear Nemytskij operators in Hölder spaces of integral type which have much better properties than classical Hölder spaces.

Key Words and Phrases: Initial value problem, Caputo derivative, singular integral equation, Riemann-Liouville operator, Nemytskij operator, integral-type Hölder space, Schauder fixed point theorem, Darbo fixed point theorem.

2020 Mathematics Subject Classification: 26A33, 47H10, 47J05, 26A15, 26A16, 34B16, 45D05, 45E05, 45G05, 47H30.
\end{abstract}

\section{REFERENCES}

[1] J. Appell, J. Banaś, N. Merentes, Bounded Variation and Around, De Gruyter, Berlin 2013.

[2] J. Appell, E. De Pascale, P.P. Zabrejko, An application of B.N. Sadovskij's fixed point principle to nonlinear singular equations, Zeitschr. Anal. Appl. 6(3)(1987), 193-208.

[3] J. Appell, B. López, K. Sadarangani, Existence and uniqueness of solutions for nonlinear fractional initial value problems involving Caputo derivatives, J. Nonlin. Var. Anal. 2(2018), 25-33. 
[4] A.A. Babaev, The structure of a nonlinear operator and its applications (Russian), Uchen. Zapiski Azerbajdzh. Gos. Univ., 4 (1961), 13-16.

[5] J. Bergh, J. Löfström, Interpolation Spaces, Springer, Berlin 1976.

[6] M.Z. Berkolajko, On a nonlinear operator which acts in generalized Hölder spaces (Russian), Trudy Sem. Funk. Anal. Voron. Gos. Univ., 12(1969), 96-104.

[7] M.Z. Berkolajko, Ya.B. Rutiskij, On operators in Hölder spaces (Russian), Dokl. Akad. Nauk SSSR, 192(1970), 1199-1201; Engl. transl.: Soviet Math. Doklady, 11(3)(1970), 787-789.

[8] M.Z. Berkolajko, Ya.B. Rutiskij, Operators in generalized Hölder spaces (Russian), Sibir. Mat. Zhurn., 12(5)(1971), 1015-1025; Engl. transl.: Siber. Math. J., 12(5)(1971), 731-738.

[9] G. Darbo, Punti uniti in trasformazioni a codominio non compatto, Rend. Sem. Mat. Univ. Padova, 24(1955), 84-92.

[10] R.A.C. Ferreira, Existence and uniqueness of solutions for two-point fractional boundary value problems, Electronic J. Diff. Equ., 202(2016), 1-5.

[11] S.R. Firshtejn, On a compactness criterion in the space $C^{l+\alpha}[0,1]$ (Russian), Izv. Vuzov Mat., 8(1969), 117-118.

[12] A.I. Gusejnov, Kh.Sh. Mukhtarov, Introduction to the Theory of Nonlinear Singular Integral Equations (Russian), Nauka, Moscow 1980.

[13] A.A. Kilbas, H.M. Srivastava, J.J. Trujillo, Theory and Applications of Fractional Differential Equations, Elsevier, Amsterdam 2006.

[14] S.G. Krejn, Yu.I. Petunin, E.M. Semenov, Interpolation of Linear Operators (Russian), Nauka, Moscow 1978; Engl. transl.: Amer. Math. Soc. Monographs, Providence R.I. 1982.

[15] A. Matkowska, On the characterization of Lipschitzian operators of substitution in the class of Hölder's functions, Zeszyty Nauk. Politech. Łódz. Mat., 17(1984), 81-85.

[16] J. Matkowski, Integrable solutions of functional equations, Diss. Math., 127(1975), 1-68.

[17] J. Matkowski, Functional equations and Nemytskij operators, Funkc. Ekvacioj, 25(1982), 127132.

[18] Kh.Sh. Mukhtarov, A.M. Magomedov, On compactness criteria and imbedding theorems (Russian), Sbornik Nauchn. Soobshch. Dagest. Gos. Univ., 5(1970), 34-42.

[19] I. Rus, A. Petruşel, G. Petruşel, Fixed Point Theory, Univ. Press, Cluj, 2008.

[20] B.N. Sadovskij, On measures of noncompactness and condensing operators (Russian), Probl. Mat. Anal. Slozhn. Sistem VGU, 2(1968), 89-119.

Received: December 19, 2018; Accepted: March 22, 2019. 
